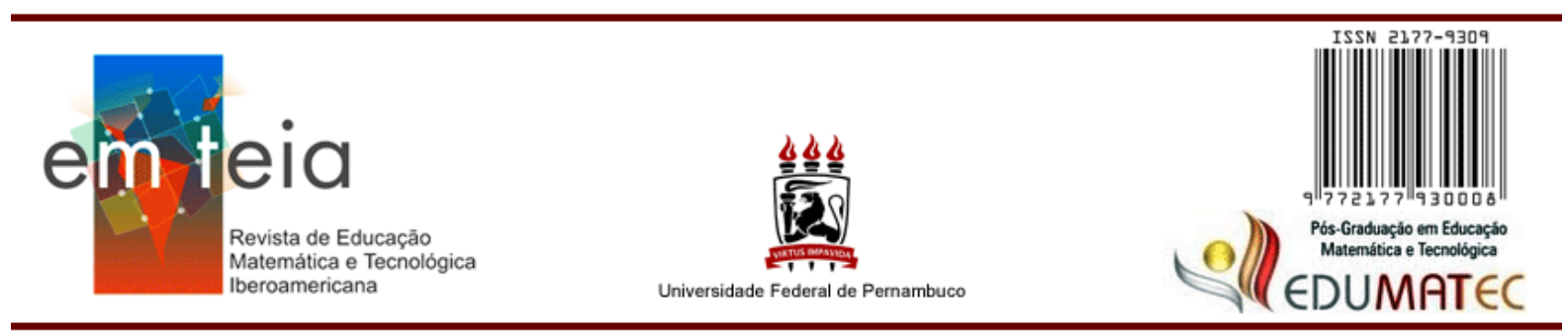

\title{
A SABOTAGEM COMO ARTE (ARTEIRA) PARA UMA DOCÊNCIA NÃO-FASCISTA
}

\author{
Mari Terezinha Panni \\ Mestranda em Educação em Ciências, Química da Vida e Saúde \\ UFRGS - RS - Brasil \\ E-mail: maripanni@gmail.com \\ Claudia Glavam Duarte \\ Dra. em Educação \\ UFRGS - RS - Brasil \\ E-mail: claudiaglavam@hotmail.com
}

\section{Resumo}

O presente artigo tem por objetivo problematizar a docência de dois professores de uma escola do campo que trabalham com classes multisseriadas. Sabemos que a organização multisseriada escapa do que é estipulado como norma, assim, o modelo seriado age sobre a conduta dos professores dentro da maquinaria educacional impondo normas para as salas de aulas. No entanto, o docente da multisseriada desestabiliza o dispositivo seriado, emergindo, dessa forma, um pensamento/ação que faz fissuras a fim de libertar-se ou, quem sabe, ao menos, minimizar a ação das "categorias do Negativo" propostas por Foucault, resultando em uma docência-sabot. Nas práticas de sabotagem surge uma "arte-arteira", uma docência que permite o devir, que potencializa as relações que permeiam o espaço multisseriado e onde são produzidas forças que vão de encontro com o que é estabelecido pela maquinaria escolar. Para fazer este estudo, utilizamos ferramentas foucaultianas e deleuzianas para entender como os saberes/fazeres dos docentes se configuram nesse espaço e como é potencializada a falta de formação específica para os professores que atuam em classes multisseriadas.

Palavras-Chave: Sabotagem, docência, arte-arteira, educação do campo, multisseriação.

\section{THE SABOTAGE AS ART (TRINKET) FOR A NON-FASCIST TEACHING}

\begin{abstract}
The present article has as objective to problematize the teaching of two teachers of a school of the field that work with multi-serialized classes. We know that the multi-series organization escapes what is stipulated as a norm, so the serial model acts on the behavior of teachers within the educational machinery imposing norms for the classrooms. However, the multi-serial teacher destabilizes the serial device, thus emerging a thought / action that cracks in order to free itself or, at least, minimize the action of the "categories of Negative" proposed by Foucault, resulting in a sabot teaching. In the practices of sabotage an "art-arteira" arises, a teaching that allows the becoming, that potentializes the relations that permeate the multi-series space and where they are produced forces, that are in
\end{abstract}


agreement with what is established by the school machinery. In order to do this study, we use Foucaultian and Deleuzian tools to understand how teachers' knowledges are configured in this space and how the lack of specific teacher education.

Keywords: Sabotage, teaching, art- trinket, rural education, multiseriate.

\section{Introdução}

Faça crescer a ação, o pensamento e os desejos por proliferação, justaposição e disjunção, mais do que por subdivisão e hierarquização piramidal; - Liberese das velhas categorias do Negativo (a lei, o limite, a castração, a falta, a lacuna), que o pensamento ocidental, por um longo tempo, sacralizou como forma do poder e modo de acesso à realidade. Prefira o que é positivo e múltiplo; a diferença à uniformidade; o fluxo às unidades; os agenciamentos móveis aos sistemas. Considere que o que é produtivo, não é sedentário, mas nômade [...] (FOUCAULT, 1991, p. 2).

Estas são algumas das proposições/provocações escritas por Foucault para prefaciar uma obra/acontecimento, que no fervor de maio de 68, dilacerava a psiquiatria e a psicanálise: o Anti-Édipo: capitalismo e esquizofrenia, de Deleuze e Guattari (1991). Segundo Foucault, trata-se de uma obra de ética bem-humorada que não exclui a seriedade e a densidade das questões que problematiza e articula, de forma bastante consistente, a Ars erótica, a ars theoretica e a ars política, e que, por este motivo, deveria ser abordada como uma obra arte. Por esta condição, o filósofo anuncia os três adversários que a obra de Deleuze e Guattari encontraria: os funcionários da verdade, os técnicos do desejo e, principalmente o maior de todos, o fascismo, inclusive aquele que insiste em habitar nossa existência, por intermédio do insistente desejo ao poder e da busca à verdade. No entanto, contra todas as formas de Fascismo, Foucault propõe-nos, dentre outras coisas, a propagação de um pensar a partir de novos agenciamentos que, de forma nômade, não cansem de vagamundear em busca do fissurar e do burlar o pensamento cristalizado e o poder que o anima e, para isto, insiste que, dentre outras coisas, devamos nos liberar "das velhas categorias do Negativo".

Neste texto, queremos apostar em um pensamento/ação que faz fissuras a fim de libertar-se ou, quem sabe, ao menos, minimizar a ação de tais categorias para pensarmos uma docência não-fascista. Com esta intenção, defendemos a sabotagem, enquanto uma arte (arteira), como uma ação possível para a minimização da força que possui este Negativo - "a lei, o limite, a castração, a falta, a lacuna" no âmbito da docência. E para isto fazemos a aposta na docência-sabot que explicamos a seguir. 


\section{A docência-sabot}

Ao percorrermos a origem etimológica da expressão sabotagem verificamos que esta provém da língua francesa "sabot" que significa "tamanco" (DICIONÁRIO ETIMOLÓGICO, 2018). A articulação com o entendimento de sabotagem, enquanto ato proposital que danifica, que impede o funcionamento de certos mecanismos, que prejudica algo de forma voluntaria, está associada ao período da Revolução Industrial, especificamente ao ato de trabalhadores que, descontentes com suas condições trabalho, colocavam seus tamancos nas máquinas das fábricas para causar-lhes danos e paralisações. Silvo Gallo (2003) ao reter a imagem de tais grevistas nos instiga a agir como "ludistas pós-modernos". Sua inspiração advém do operário de uma fábrica têxtil, Ned Ludd, que destruiu totalmente os teares mecânicos de uma fábrica na Inglaterra, num sinal de revolta contra os efeitos da Revolução Industrial no início do século XIX. Gallo, acompanhando as táticas deste operário, quer impedir a máquina de funcionar, danificar e estancar o automatismo das ações contra os efeitos de uma educação maior entendida como aquela baseada nos "planos decenais e nas políticas públicas de educação, dos parâmetros e das diretrizes, aquela da constituição e da Lei de Diretrizes e Bases da Educação Nacional, pensada e produzida pelas cabeças bempensantes a serviço do poder" (GALLO, 2003, p. 78). Assim, tal ato quando pensado no âmbito da educação nos remete à relação de forças no embate entre a educação maior e a educação menor, pois as táticas da educação menor, entendida como "um ato de revolta de resistência. Revolta contra os fluxos instituídos, resistência às políticas impostas; sala de aula como trincheira, como a toca do rato, o buraco do cão" (2003, p. 78) são bastante similares as dos grevistas que trabalhavam nas fábricas.

Neste sentido, acreditamos que, talvez, uma das condições necessárias para pensarmos outro tipo de educação seja uma docência-sabot que se movimenta "fazendo artearteiramente" contra a maquinaria escolar. Docência que pode propiciar o rompimento das relações de uma organização educacional hierarquizada, que se produz em um sistema préestabelecido, homogêneo, e que, com suas manobras, tende a bagunçar o estabelecido, mexer com o que está programado, deixando rastros por onde passa através das suas metodologias desconectadas da linearidade e do homogêneo. Frente a essas proposições, esta docência tende ao novo, ao inusitado e desprende inquietações sobre esta forma desconcertante de ser professor dentro de um sistema educacional estruturado. No limite é uma docência que institui micro-revoluções "como aqueles sindicalistas norte-americanos do começo do século, que pegavam um trem para o Oeste e que, a cada estação atravessada, paravam para fundar uma 
célula, uma célula de luta" (NEGRI, 2001, p. 24). Nossa hipótese é que esta docência que “emperra" a máquina ou que, minimamente, deforma a esteira de produção, afirma uma educação que

[...] não está subordinada à representação, à adequação da verdade, ao dado, antes disso, os instrumentos para pontuar os traços vitais para a Educação percorrem movimentos de forças, de resistências, que podem deformar a forma estabelecida por currículos escolares, saberes prontos, conhecimentos interpretados que desejam modulação universal. Com isso, seria possível compor cores novas e vibrantes ao novo corpo que deseja nascer, um corpo alegre, desejante [...] (BRITO, 2015, p. 57).

Tal deformação poderia ser acionada por dois movimentos: primeiro aquele que estanca a maquinaria e, em segundo, aquele que a faz ir diferindo de sua função calcada nas leis e interdições e que, em efeito, vai produzindo outras formas de subjetivação docente.

Para pensarmos estes movimentos elencamos uma sala de aula diferenciada: a multisseriada. Cabe ressaltar que sala de aula ou escola multisseriada refere-se ao tipo de organização escolar que abriga em uma mesma sala alunos de diferentes séries/anos escolares, ocorrendo com muita frequência, em áreas rurais. Essa forma de organização nos parece que pode se constituir em um território que propicia o confronto do professor com as relações de força que o conformam a ser, pensar e agir dentro das normas estabelecidas pela seriação. Dito de outra forma, acreditamos que a existência de escolas/classes multisseriadas poderia ser tomada como uma condição propícia no sentido de ali se fazer germinar uma docênciasabot que reaja aos modelos totalitários e homogeneizantes, pois, o docente desta forma de organização escolar vivencia embates cotidianos visto que esta configuração "destitui a série como princípio ordenador e como fundamento para as ações pedagógicas" (DUARTE; TASCHETTO, 2014, p. 53) e provoca abalos em uma zona de conforto historicamente construída e naturalizada.

\section{A Multisseriação: território potente para uma sabotagem arteira}

As escolas que abrigam a multisseriação como forma de organização dos tempos/espaços escolares estão, em sua quase totalidade, vinculadas às áreas rurais e tornamse, na maioria das vezes, a única opção ao sistema escolar de sujeitos que lutam para manter a escola em suas comunidades. Historicamente, a origem da multisseriação, ainda presente nos tempos atuais, está vinculada a um período da história educacional brasileira, especificamente no período denominado de Brasil colônia, em que professoras leigas, muitas vezes alguém da 
própria comunidade, agrupavam, indiferentes à idade, crianças a fim de ministrarem suas aulas. Em 1827, esta forma de organização foi referendada pela Lei Geral do Ensino que adotou o Método Lancasteriano em que alunos considerados mais avançados ensinavam os que se pressupunham em níveis anteriores. De acordo com Janata e Anhaia (2015), foi somente no período republicano (1889), com o surgimento dos grupos escolares, que o modelo seriado surgiu como "a forma ideal" de organização do espaço educativo. Tal ideal de organização segue persistindo nos dias atuais visto que os processos de nucleação de escolas vêm ocasionando o fechamento de escolas nas comunidades rurais.

Esta concepção tem gerado, ainda hoje, a ideia de que a multisseriação deva ser combatida e que seu desaparecimento resultaria de um processo que se propunha evolutivo. A seriação, considerada então o modelo ideal de configuração para os espaços escolares, irá funcionar tal qual um dispositivo, pois, para se estabelecer, ela organizará e colocará em funcionamento

[...] um conjunto decididamente heterogêneo que engloba discursos, instituições, organizações arquitetônicas, decisões regulamentares, leis, medidas administrativas, enunciados científicos, proposições filosóficas, morais, filantrópicas. Em suma, o dito e o não dito são os elementos do dispositivo. O dispositivo é a rede que se pode tecer entre estes elementos (FOUCAULT, 2000, p. 244).

Assim, o conjunto formado por elementos tais como a arquitetura escolar que abriga diferentes salas de aula, uma para cada ano escolar, o currículo escolar definido para cada faixa etária, os discursos de especialistas que afirmam as potencialidades e fragilidades de cada período da infância, entre outros, legitimam e são legitimados pelo dispositivo da seriação. Tal dispositivo age sobre a conduta dos professores afirmando o que deve e pode ser feito em relação a cada grupo de crianças que são distribuídas, de acordo com sua idade, nos diferentes anos escolares.

No entanto, apesar de todos os esforços para manter a organização escolar por séries/anos, a multisseriação segue resistindo e tal resistência tem contribuído para a subversão de linhas que tentam guardar relações biunívocas entre a verdade e o mundo. Segundo dados do Censo Escolar de 2011, 45.716 escolas do Brasil possuíam salas multisseriadas. Destas, 42.711 ficam na zona rural e 3.005 na zona urbana - são 1.040.395 matrículas na zona rural e 91.491 na urbana. Para além do argumento, extremamente relevante, que afirma a necessidade da permanência de escolas situadas na própria 
comunidade, nossa aposta está exatamente na subversão que ela, muitas vezes, pode propiciar ao fazer docente.

Neste artigo discutimos aspectos de uma pesquisa de Mestrado vinculada ao Programa de Pós-Graduação em Ciências, Química da Vida e Saúde da Universidade Federal do Rio Grande do Sul (UFRGS) que está sendo desenvolvida no espaço de uma escola estadual rural, mais especificamente na comunidade de Pinheirinhos, quarto distrito do município de Santo Antônio da Patrulha, interior do Estado do Rio Grande do Sul. Distante, aproximadamente, um quilometro da rodovia, o acesso para se chegar à escola é de chão batido, uma estrada precária com muitas pedras, buracos e subidas íngremes. Nas suas redondezas quase não se observam moradores, o cenário é composto de campos, arvoredos de todos os tipos e algumas frutíferas: pés de laranja e bergamota. Alterando este cenário está o cemitério comunitário. Nos fundos do terreno temos um galpão aberto que abriga uma horta construída pelas crianças.

A escola é composta por uma diretora e três docentes. Dois estão vinculados ao magistério estadual e uma docente que foi cedida pelo Município. Estes atendem trinta e nove alunos do primeiro ao sétimo ano e dezesseis na educação infantil, totalizando assim 55 alunos. Mesmo que a oferta da Educação Infantil não seja de responsabilidade da rede estadual de ensino, essa escola atende esses alunos, em parceria com o município. Assim, excetuando-se a Educação Infantil, a escola tem 3 turmas, todas no modelo da multisseriação. A primeira reúne alunos do primeiro, segundo e terceiro anos, a segunda turma abriga o quarto e quinto anos e a última agrupa alunos do sexto e sétimo anos. Para este trabalho investigativo, acompanhamos o trabalho dos professores de duas turmas multisseriadas: a primeira e a segunda supracitadas.

Do ponto de vista metodológico, o material empírico aqui apresentado foi composto de entrevistas semiestruturadas com os docentes e as observações da rotina escolar anotadas em um caderno de campo. As entrevistas foram transcritas e, para analisá-las, procuramos acompanhar a dupla orientação feita por Nietzsche (2001) no outono de 1886. Por um lado, a suspensão de nossa "vontade de verdade" - vontade tão requerida aos sujeitos modernos que, na tentativa de explicar o mundo, tentam aproximar-se cada vez mais da "realidade em si mesma" para encontrar-lhe o "verdadeiro" fundamento - e, por outro, o imprescindível exercício - tão relevante para as perspectivas pós-estruturalistas - de limitarmo-nos à exterioridade, à superfície das formas, a tons e palavras como recurso às análises que pretendem dar visibilidade à positividade "do dito". Acreditamos que o caráter persuasivo 
dessa orientação, feita por Nietzsche, seja imperativo nestes tempos para exercitar a curiosidade foucaultiana, "a única espécie de curiosidade que vale a pena ser praticada com um pouco de obstinação: não aquela que procura assimilar o que convém conhecer, mas a que permite separar-se de si mesmo" (FOUCAULT, 2001, p. 13). Dito de outra forma, o material empírico que foi constituído nesta investigação e o que conseguimos evidenciar é o que "vimos", ou melhor, o que aprendemos a ver, no interior dos aparatos teóricos em que nos deslocamos e que não poderia ser diferente, pois "[...] é o olhar que botamos sobre as coisas que, de certa maneira, as constitui" (VEIGA-NETO, 2002, p. 30) e que, uma vez constituídas, experimentam diferentes processos de significação. No entanto, temos ciência de que "[...] por mais que se diga o que se vê, o que se vê não se aloja jamais no que se diz, e por mais que se faça ver o que se está dizendo por imagens, metáforas, comparações, o lugar onde estas resplandecem não é aquele que os olhos descortinam, mas aquele que as sucessões da sintaxe definem" (FOUCAULT, 1999, p. 120). Dessa forma, o que se vê sempre escapa ao dito que se pretende capturar. Portanto, o que "vimos" é apenas um modo de ver entre a multiplicidade de sentidos que abriga o que se deixa ver; e o que escrevemos é apenas uma possibilidade de escrita, pois, "quando fazemos coisas com as palavras, do que se trata é de como damos sentido ao que somos e ao que nos acontece, de como juntamos as palavras e as coisas, de como nomeamos o que vemos ou o que sentimos e de como vemos ou sentimos o que nomeamos" (LARROSA, 2004, p. 153). E o que vimos e sentimos?

\section{As Artes arteiras de uma docência-sabot}

Nas primeiras idas a campo, nosso interesse esteve centrado na observação dos saberes/fazeres dos professores que trabalhavam nas classes multisseriadas, especificamente quando se detinham em ensinar matemática. Em um primeiro momento, a destreza dos professores nos levava a inferir que ambos teriam tido alguma formação específica para o trabalho com estas turmas. No entanto, ficou evidenciado que ambos professores não tiveram uma formação específica para o trabalho pedagógico em turmas multisseriadas. Suas aprendizagens foram ocorrendo no fazer-se docente frente a esta configuração escolar. Segundo alguns depoimentos:

Durante minha formação, pouco se falou em multisseriada, nada de aprendizagem concreta, aprendi mesmo na prática, dentro da escola, primeiro como aluna e também junto com minha mãe que já era professora de classe multisseriada, dessa mesma escola que trabalho, e depois sozinha, nas vivências, nas práticas. 
Sempre pensei assim, quando cai no magistério e cai mesmo e gostei e não sei mais fazer outra coisa. E daí eu sempre tinha uma coisa, queria fazer o trabalho de conclusão (curso de Pedagogia) voltado para minha comunidade para ajudar, para desenvolver, para crescer, aí começou a surgir à história da educação do campo, aí eu falei com a minha professora; eu quero, mas realmente passamos muito trabalho não tinha leitura... Não tive nenhuma disciplina na faculdade, não aprendi nada de multisseriada, foi só o meu interesse no trabalho de conclusão que teve relação com a escola do campo.

De acordo com os excertos acima é possível inferir que foram "as práticas, as vivências" que funcionaram/funcionam como base formativa para estes docentes, pois a graduação parece ter se calado frente a este modelo de organização educacional. Esta invisibilidade nas discussões acadêmicas, em específico em cursos de licenciatura na graduação, já foi evidenciada por Duarte e Taschetto (2014, p. 52) ao afirmarem, no que se refere à multisseriação, "uma estranha invisibilidade nos cursos de formação de professores e nas pesquisas que tenham como eixo problematizador questões inerentes a essa realidade". Levantamos como hipótese que, talvez, esta condição seja propulsora para que o professor se permita fazer algumas artes/arteiras visto que não foram constituídas didáticas, currículos, avaliações, normas... para seu trabalho docente com as multisseriadas. Obviamente não defendemos neste texto a não formação docente, mas, desconfiamos que esta "falta" pode abrir espaço para que emerjam forças criadoras e inventivas de experiências outras. Nossa crítica se faz a uma formação que formata, que homogeneíza e que não abre brechas à criação. Como afirma Corazza (2016, p. 1324), "Quanto menos o trabalho docente for limitado a regras fixas e, quanto mais sensível permanecer aos movimentos do informe (VALÉRY, 2003) - ainda não reconstruído por operações racionais -, mais dispostos estaremos à invenção de novas formas". Assim a "falta de manuais de instrução" para o exercício da docência destes professores talvez possa ser considerado como condicionante de um espaço para práticas de liberdade entendidas como movimentos de transgressão, ruptura e criação de novas formas de subjetividade (CASTRO, 2009); no caso específico desta pesquisa, subjetividades docentes. No entanto, a força do dispositivo da seriação ainda leva um dos docentes a afirmar que

[...] a gente, às vezes, se sente perdido sem amparo, amparo de algum pensador de algum autor [para o trabalho com multisseriada]. Então a gente acha que isso ainda esteja em construção, não existe ainda uma forma certa. 
Dessa forma, é possível inferir que este professor vivencia uma liberdade agonística, pois por um lado a falta de formação lhe permite criar, inventar estratégias, mas, por outro lado, ele se sente desamparado, não legitimado pelos "especialistas" que "detém o poder de dizer o verdadeiro e o válido para o campo educacional".

Porém, Foucault (2006) afirma que a liberdade dos sujeitos não é assegurada pelas instituições e pelas leis que a garantem, ou seja, seria necessário evitarmos pensar a liberdade como aquela concedida por um aparato jurídico, pela lei ou pelo que dizem os especialistas. A liberdade é algo que devemos exercitar, e não se reduz à questão da vontade, da escolha ou do livre-arbítrio. Para o filósofo, a liberdade é algo necessário para se compreender as relações de poder e é fundamental para o exercício do poder. Como destaca Kohan (2003, p. 89),

o exercício do poder pressupõe a prática de liberdade. Esta prática não é exercida por indivíduos soberanos ou autônomos, constituídos previamente, mas por indivíduos que, na trama das relações de poder que os atravessam, podem perceber outras coisas, diferentemente daquelas que estão percebendo.

Então, a liberdade não é o outro lado do poder, não existe uma relação de exclusão entre eles, a liberdade não significa ausência de poder. São outras percepções, ações e, em efeito, criações que se dão dentro da própria trama em que se engendra o poder que institui algumas práticas de liberdade. Pode-se assim dizer que nesta relação [poder-liberdade] se faz presente um sentimento de agonia, pois se tem, ao mesmo tempo, "uma incitação recíproca e de luta; trata-se, portanto, menos de uma oposição de termos que se bloqueiam mutualmente do que de uma provocação permanente" (SAMPAIO, 2007, p. 96).

É, neste ponto, nesta provocação permanente que sofre o docente da multisseriada que se faz presente seu processo agonístico de liberdade pois, nesta relação, existe um movimento onde a liberdade não ocorre de forma total, visto que ela está a todo instante entrelaçada ao poder, especificamente ao poder do dispositivo da seriação, mas, ao mesmo tempo este docente vivencia um território, o da Multisseriação, que lhe propicia a invenção de outras experiências. Portanto, a relação que existe entre o poder e a liberdade não é simples, pois, ao mesmo tempo em que a liberdade pode ser condição para o poder, pode também resistir a ele "como um movimento micro, de pequenas revoltas diárias" (LARROSA, 2000, p. 334). São estas micro resistências que presenciamos em algumas de nossas observações. 


\section{Micro resistências: sabotando a série/ano}

A continuidade do trabalho de campo nos fez perceber estes micros movimentos, estas pequenas revoltas diárias de que nos fala Larrosa (2000), pois identificamos que, muitas vezes, os professores não separavam os alunos, apesar da sala conter três diferentes anos escolares. Nossa hipótese inicial era a de que os alunos seriam separados por fila: a fila do primeiro ano, do segundo etc. No entanto, a racionalidade que imperava parecia não querer instituir classificações e hierarquizações. Como afirmou uma professora: eu procuro nem fazer essa divisão na minha cabeça sabe? Porque eu sei que ela não vai dar certo! Ao questionarmos sobre este fato as respostas foram as seguintes:

[...] eu não impeço eles de interagirem um com o outro, ou de certa forma, o Arthur no ano passado (segundo ano) e outro coleguinha (terceiro ano), que às vezes eles estavam fazendo um problema de multiplicação e ele dizia: o fulano quanto que é tanto vezes tanto? Ah! é tanto...

Aí professor posso tentar fazer aquela lá também? Claro pode tentar fazer... Eu não posso deixar de provocar ele, ou fazer com que ele em certo momento ajude aquele outro aluno a resolver aquele problema, porque ele também está aprendendo.

É o que acontece às vezes, eu no início do ano eu tentei fazer, que deu certo, eu só tinha um na verdade no quarto ano, agora eu tenho dois, mas eu só tinha um, daí eu combinei com eles, com os pais dele, que eu ia tentar botar ele praticamente junto com o quinto, sabe a interpretação textual ... se eu visse que ele não ia dar conta daquilo, daí eu iria dar uma segurada, no início ele deu uma patinada, porque nas minhas alunas praticamente, elas fazem os trabalhos sozinhas.

Daí eu vi que ele sabia os nomes dos números, que ele sabia essa classificação de unidade, dezena centena e milhar ...então aquilo ali eu fui dando e fui vendo que ele sabia e fui e fui indo, recapitulei com o quinto, porque vou saber se o quinto ainda se lembra o que leu, se não ficou nada e aí fui indo, fui indo... o que dá certo dá, o que não dá eu volto, porque tem uns que, as vezes os do quinto, tem umas do quinto que as vezes precisam de mais atenção, eles conseguem trabalhar em grupo e desenhar todo mundo junto no mesmo cartaz, assim uns quatro, cinco. Eu não consigo assim, eu procuro nem fazer essa divisão na minha cabeça sabe? Porque eu sei que ela não vai dar certo.

Assim, a interação, a provocação e o tatear o caminho "e fui e fui indo" parecem ser os alicerces de uma prática que se constitui ao fazer-se. Não existem certezas, pontos exatos de chegada. Parece-nos que a "não divisão" institui uma docência que, em meio a um caos, faz 
sucumbir a relação de força que busca estruturar a educação maior em idade/ano escolar. Ocorreria aí uma situação que movimenta mais o devir em relação ao dever? Acreditamos que sim, pois o processo educativo parece se movimentar em torno dos encontros, de uma educação sem imagens fixas, que é "retirada do campo das modelações para as modulações, variações, encontros, interseções [...]" (BRITO, 2015, p. 39). E aqui encontramos a força para a constituição de uma docência não-fascista visto que resiste às Leis do Negativo. Não há garantias do ponto de chegada. Trata-se de um movimento de ziguezaguear "e aí fui indo, fui indo... o que dá certo dá, o que não dá eu volto", que segue o fluxo determinado pelo instante em que se efetua. Dito de outra forma, são os movimentos instituídos no momento os condicionantes para prosseguir caminhando e estas pequenas incisões/sabotagens na estrutura fazem danificar os automatismos da maquinaria escolar que delimita as aprendizagens em função da idade do aluno. Assim, a pretensão de classificações e hierarquizações encontra obstáculos em uma turma multisseriada, pois, há encontros, interações, movimentos de classes que ora se agrupam de uma determinada forma, ora de outra. O arrastar cadeiras mostra a intensidade de tais encontros e faz criar os bandos e,

[...] o que há de bom em um bando, em princípio cada um cuida de seu próprio negócio encontrando ao mesmo tempo os outros; cada um tira seu proveito, e que um devir se delineia, um bloco, que já não é de ninguém, mas está "entre" todo mundo, se põe em movimento como um barquinho que as crianças largam e perdem e que outros roubam. (DELEUZE; PARNET, 1998, p. 17).

Assim, não há identidade de grupo: grupo do primeiro ano, do segundo ano etc., mas encontros, afinidades que surgem e se desfazem, são momentâneos. Em outras palavras, a configuração de bando rascunha, abre brechas, cada um cuida do seu próprio interesse que poderá ir ao/de encontro com os interesses de outros. Na sala "singularidades se conectam, processos ou devires se desenvolvem, intensidades sobem ou descem" (DELEUZE; PARTNET, 1998, p. 183).

[...] nós somos uma turma, não interessa série, só que isso ainda é uma vício do próprio professor, o segundo ano, terceiro ano, a fila ou alguma coisa assim, isso eu acho que as instituições têm que começarem a se organizarem, para que isso em uma multisseriada fique claro que é uma turma, a turma, e não são várias turmas que tenho ali. 
(...) Então vamos dizer que ele está no segundo ano e ainda não conseguiu fazer isso (soma e multiplicação) ele vai auxiliar dessa forma, onde eu vou observar se ele sabe contar já ou não, se ele já consegue a partir da conta que ele faz, se ele conhece o valor numérico, se eu já posso perguntar o valor numérico para a multiplicação para ele também, né, mas como eu pergunto para todos, ele também vai raciocinar nesse sentido, até com que ele veja que ele perceba que a relação da multiplicação é quantidade e o número de vezes que pega. E daí a gente percebe que alguns começam a perceber isso e daí eles vão, será que é ou não é ... e vai gerando aquela dúvida neles né, que é o conhecimento, e daí a gente vai tirando as dúvidas com aqueles que já sabem, porque tem aqueles que sabem né... aí tu pergunta, mas como, porque esse valor deu assim? Daí faz com que eles expliquem, então eles estão explicando uma coisa para os outros que também já estão pegando aquele conteúdo, trabalhando todas as séries ao mesmo tempo, a turma

Percebemos, nos excertos acima e nas observações realizadas, que são contingentes as formações de bandos na sala. Diferentes agrupamentos/encontros ocorrem e, antes mesmo de serem identificados, se desfazem. Em alguns momentos a docência-sabot busca não distinguir idades e ano escolar, simplesmente algo é disparado para todos e as apropriações se fazem de maneira singular. Em outros momentos o dispositivo da seriação faz imperar situações que são cotidianas no modelo seriado. Assim, de vez enquanto, parecem ser colocados biombos, paredes imaginárias na sala e separam-se os anos escolares. Neste momento, o dispositivo da seriação estabelece atividades que são específicas para cada ano. No entanto, por mais que tal dispositivo aja com força sobre os fazeres e saberes docentes, identificamos várias situações em que os professores escaparam de tal força e propuseram experiências outras. Acreditamos que são estas práticas que fissuram a norma que acabam por constituir uma docência-sabot não fascista.

\section{Considerações Finais}

Este artigo buscou evidenciar a "arte arteira" de uma "docência-sabot" que faz provocações ao liberar pensamentos/ações "das velhas categorias do Negativo" impostos pelo modelo escolar seriado. A análise dos saberes e fazeres de dois docentes de classes multisseriadas nas aulas de matemática nos propicia inferir que as suas práticas desestabilizam a organização seriada e, em efeito, fazem emergir outras formas de exercício da docência em que "os processos são os devires, e estes não se julgam pelo resultado que os findaria, mas pela qualidade dos seus cursos e pela potência da sua continuação" (DELEUZE; 
PARTNET, 1998, p. 183). Assim, este processo é paulatinamente elaborado dentro de um contexto marcado pela heterogeneidade.

Durante as entrevistas, em vários momentos, os professores expressaram sua angústias frente à falta de uma formação específica para um trabalho pedagógico com turmas multisseriadas. Tal fato nos fez inferir que a invisibilidade de discussões, no âmbito dos cursos de licenciatura, tem propiciado a construção de docência inventiva que se produz no exato momento em que se efetua. Dito de outro modo, a falta de manuais de instrução do "faça assim! Ou siga o modelo" tem gerado diferentes experiências educativas que, impulsionadas por movimentos criativos, minimizam a força do dispositivo da seriação. Assim, tal lacuna abre espaço para os devires e para a constituição de uma "docência-sabot" que se efetua em um processo de resistência ao que é imposto, pois, resistir é "enveredar para outros modos de subjetivação tomando atalhos por onde o discurso que determina a verdade do sujeito não entra" (SOUZA, 2003, p. 41). Poderíamos pensar que a docência-sabot permite a configuração de brechas, de um processo educativo ainda sem imagens, pois

É possível pelas brechas, pelas fissuras em sala de aula, pelo entre lugar, pelo meio da ação educativa, promover processos inventivos e criadores e fazer a diferença escorrer, pois é nesse espaço da fronteira que se pode pensar uma educação em trânsito [...] (BRITO, 2015, p. 35).

É no sentido de perceber esta educação em trânsito que nosso olhar para o campo foi mobilizado. Ao longo de nossa pesquisa fomos percebendo que a sala de aula multisseriada é um espaço de resistência, pois ela tende a romper com o estabelecido fazendo com que emerja movimentos que desestabilizam o que é naturalizado pela maquinaria educacional. Tal condição seria, em nosso entender, propício para a configuração de novas subjetividades docentes, principalmente para uma docência-sabot que busca fazer arte-arteiramente.

\section{REFERÊNCIAS}

BRITO, Maria dos Remédios de. Entre as linhas da Educação e da diferença. São Paulo: Editora Livraria da Física, 2015.

CASTRO, Edgardo. Vocabulário de Foucault: um percurso pelos seus temas, conceitos e autores. Trad. de Ingrid Muller Xavier. Belo Horizonte: Autêntica, 2009.

CORAZZA, Sandra. Currículo e Didática da Tradução: vontade, criação e crítica. Educação \& Realidade, Porto Alegre, v. 41, n. 4, p. 1313-1335, out./dez. 2016. 
DELEUZE, Gilles; PARNET, Claire. Diálogos. São Paulo: Escuta, 1998.

DICIONÁRIO ETIMOLÓGICO: etimologia e origem das palavras. Sabotagem. Disponível em: 〈https://www.dicionarioetimologico.com.br/busca/?q=sabotagem>.

DUARTE, Claudia Glavam; TASCHETTO, Leônidas Roberto. A conversar com estátuas. Currículo sem Fronteiras, v. 14, n. 1, p. 50-61, jan./abr. 2014.

FOUCAULT, Michel. Anti-Édipo: introdução à vida não-facista. In: DELEUZE, Gilles; GUATTARI, Félix. Anti-Édipo. Rio de Janeiro: Hólon Editorial, 1991. Disponível em: <https://pimentalab.milharal.org/files/2012/05/foucault_anti_edipo.pdf>. Acesso em: 14 jun. 2018.

FOUCAULT, Michel. As palavras e as coisas. São Paulo: Martins fontes, 1999.

FOUCAULT, Michel. Os intelectuais e o poder. Conversa entre Michel Foucault e Gilles Deleuze. In: FOUCAULT, Michel. Microfísica do Poder. Rio de Janeiro: Graal, 2000.

FOUCAULT, Michel. História da sexualidade II: o uso dos prazeres. Rio de Janeiro: Graal, 2001.

FOUCAULT, Michel. Ditos e Escritos II: Ética, Política e Sexualidade - Vol. V. 2. ed. Rio de Janeiro: Forense Universitária, 2006.

GALLO, S. Deleuze \& a educação. Belo Horizonte: Autêntica, 2003.

JANATA, Natacha Eugênia; ANHAIA, Edson Marcos de. Escolas/Classes Multisseriadas do Campo: reflexões para a formação docente. Educação \& Realidade. Porto Alegre, vol. 40, n. 3, jul./set. 2015.

KOHAN, Walter. Infância. Entre Educação e Filosofia. Belo Horizonte: Autêntica, 2003.

LARROSA, Jorge. Pedagogia profana. Belo Horizonte: Autêntica, 2000.

LARROSA, Jorge. Linguagem e Educação depois de Babel. Belo Horizonte: Autêntica, 2004.

NEGRI, A. Exílio. São Paulo: Iluminura, 2001.

NIETZSCHE, Friedrich. A Gaia Ciência. São Paulo: Companhia das Letras, 2001.

SAMPAIO, Simone Sobral. Foucault e a resistência. Goiânia: Editora da UFG, 2007. 
SOUZA, Pedro de. Resistir, a que Será que se resiste? O sujeito feito fora de si. In: Linguagem em (Dis)curso. Tubarão, v. 3, Número Especial, p. 37-54, 2003.

VEIGA-NETO, Alfredo. Olhares. In: COSTA, Marisa Vorraber (org.). Caminhos investigativos: novos olhares na pesquisa em educação. Rio de Janeiro: DP\&A, 2002. 